\title{
Association Between Cardiac High-Energy Phosphate Metabolism and Whole Body Metabolism in Healthy Female Adults
}

\author{
Prisca G. WIBOWO ${ }^{1}$, Sarah J. CHARMAN ${ }^{1,2}$, Nduka C. OKWOSE ${ }^{1,2}$, Lazar VELICKI $^{3}$, \\ Dejana POPOVIC ${ }^{4}$, Kieren G. HOLLINGSWORTH ${ }^{1}$, Guy A. MACGOWAN ${ }^{1,2}$, \\ Djordje G. JAKOVLJEVIC ${ }^{1,2,5}$
}

${ }^{1}$ Cardiovascular Research, Clinical and Translational and Biosciences Research Institutes, Faculty of Medical Sciences, Newcastle University, Newcastle upon Tyne, United Kingdom, ${ }^{2}$ Newcastle upon Tyne Hospitals NHS Foundation Trust, Newcastle upon Tyne, UK, ${ }^{3}$ Faculty of Medicine, University of Novi Sad, and Department of Cardiovascular Surgery, Institute of Cardiovascular Diseases Vojvodina, Novi Sad, Serbia, ${ }^{4}$ Faculty of Medicine and Pharmacy, University of Belgrade, and Cardiology Department, Clinical Centre Serbia, Belgrade, Serbia, ${ }^{5}$ Cardiovascular Research, Faculty of Health and Life Sciences, Coventry University, Coventry, United Kingdom

Received December 1, 2020

Accepted March 18, 2021

Epub Ahead of Print May 12, 2021

\begin{abstract}
Summary
Decline in cardiac high-energy phosphate metabolism [phosphocreatine-to-ATP (PCr/ATP) ratio] and whole body metabolism increase the risk of heart failure and metabolic diseases. The aim of the present study was to assess the relationship between PCr/ATP ratio and measures of body metabolic function. A total of 35 healthy women $(56 \pm 14.0$ years of age) underwent cardiac ${ }^{31} \mathrm{P}$ magnetic resonance spectroscopy to assess PCr/ATP ratio - an index of cardiac high-energy phosphate metabolism. Fasting and 2-hour glucose levels were assessed using oral glucose tolerance test. Indirect calorimetry was performed to determine oxygen consumption and resting metabolic rate. There were no significant relationships between $\mathrm{PCr} / \mathrm{ATP}$ ratio and resting metabolic rate $(r=-0.09, p=0.62)$, oxygen consumption $(r=-0.11, p=0.54)$, fasting glucose levels $(r=-0.31, p=0.07)$, and 2-hour plasma glucose $(r=-0.10$, $\mathrm{p}=0.58)$. Adjusted analysis for covariates including age, body mass index, fat mass, and physical activity, had no significant influence on the relationship between PCr/ATP ratio and body metabolism. In conclusion, the lack of relationship between cardiac PCr/ATP ratio, glucose control and metabolic rate may suggest that overall metabolic function does not influence cardiac high-energy phosphate metabolism.
\end{abstract}

\section{Key words}

Cardiac high energy phosphate $\bullet$ Metabolism

\section{Corresponding author}

D. G. Jakovljevic, Medical School, Newcastle University, William Leech Building $4^{\text {th }}$ Floor, Framlington Place, Newcastle upon Tyne, NE2 4HH, United Kingdom. E-mail: djordje.jakovljevic@newcastle.ac.uk

\section{Introduction}

Heart failure is estimated to affect 26 million people globally and its prevalence is expected to rise in coming decades (Savarese and Lund 2017). Consequently, it poses a problem in terms of financial burden of the healthcare system. In United Kingdom, $1-2 \%$ of health care expenditure is spent on heart failure while an estimated annual cost of $\$ 31$ billion was used in United States in 2012 (Cowie 2017, Mozaffarian et al. 2016). Heart failure is characterized by deterioration of contractile function resulting to inability of the heart to meet the body demands (Ventura-Clapier et al. 2004). The disequilibrium between cardiac supply and demand has led to the concept of energy starvation, in which the heart is compared to an engine out of fuel, that is central to the development of heart failure (Neubauer 2007). Changes of the cardiac metabolism's components occur in heart failure and may contribute to its development (Neubauer 2007, Ventura-Clapier et al. 2011). Cardiac 
high-energy phosphate metabolism is responsible for an intricate metabolic stability, maintaining an almost constant concentration of phosphocreatine (PCr), which is considered as an energy storage compound, and adenosine triphosphate (ATP), which is the main source of energy, when cardiac workload increases (Neubauer 2007). PCr/ATP ratio is a powerful index of cardiac highenergy phosphate metabolism measured by phosphorus31 magnetic resonance spectroscopy ( $\left.{ }^{31} \mathrm{P}-\mathrm{MRS}\right)$ (Esterhammer et al. 2014). Decline in PCr/ATP ratio has been reported in heart failure, supporting energy starvation to play a role in the development of heart failure (Beer et al. 2004, Hardy et al. 1991, Ingwall and Weiss 2004, Neubauer 2007). Diabetes is heavily linked with heart failure (Nichols et al. 2004). The Framingham study (Kannel et al. 1974) observed four and eight times increase of heart failure incidence in diabetic men and women, respectively compared to non-diabetics. In absence of diabetes, increased glucose levels were found to increase the risk of heart failure (Nielson and Lange 2005). On the other hand, abnormalities in glucose metabolism can also occur in heart failure patients and if not treated may worsen the prognosis (Tenenbaum and Fisman 2004). Several studies (Neubauer 2007, Nielson and Lange 2005) have demonstrated alterations in cardiac energetics and body metabolism that can affect heart failure but there is limited evidence reporting interaction between cardiac and whole body metabolism. Thus, the present study aims to evaluate the relationship between cardiac PCr/ATP ratio and measures of overall body metabolic function. According to the energy starvation theory, the failing heart is analogous to a weak and tired horse, and if appropriately nourished, it will be able to recover and work (Neubauer 2007). Treating heart failure by targeting energy metabolism can be a promising strategy, but it is still under investigation. Addressing the interaction between cardiac and whole body metabolism may enhance further research to address the question whether using interventions known to improve body metabolism will also lead to improved cardiac metabolism which as a potential target to treat heart failure (Neubauer 2007).

\section{Methods}

A total of 35 healthy women were recruited from local community groups affiliated with Newcastle University. Participants were included in the study if they had (i) no history of cardiovascular diseases, respiratory diseases, and other chronic conditions; (ii) normal glucose tolerance, lipid profile, blood pressure, and electrocardiogram; (iii) body mass index less than $30 \mathrm{~kg} / \mathrm{m}^{2}$. Participants were excluded if they were smokers or former smokers and if they were consuming medications known to affect cardiovascular function. This study was approved by Sunderland Research Committee (09/H0904/55). All participants provided written informed consent according to the Declaration of Helsinki.

Body composition of the participants, such as body mass, and body fat mass, was assessed using airdisplacement plethysmography (BodPod, Life Measurement Inc., California, USA). Physical activity, which is represented by average step count, was measured by a portable multisensory array (Sensewear Pro, Bodymedia Inc., Philadelphia, USA) over a 7-day period and only removed for bathing.

All participants were required to fast overnight before getting their blood samples taken at Clinical Research Facility, Royal Victoria Infirmary, Newcastle upon Tyne the following morning. After the first blood sample collection, which reflects the fasting glucose level, an oral glucose tolerance test was performed. All participants were asked to consume $75 \mathrm{~g}$ of oral glucose solution and blood sample was taken two hours later.

Metabolic variables at rest, including oxygen consumption $\left(\mathrm{VO}_{2}\right)$, respiratory exchange ratio, and carbon dioxide production $\left(\mathrm{VCO}_{2}\right)$, were determined using online gas exchange metabolic system (Metalyzer 3B, Cortex, Leipzig, Germany). Gas exchange measurements were performed in supine position for 10 min. Resting metabolic rate was calculated using Weir formula (Weir 1949) as follows:

Resting metabolic rate $(\mathrm{kcal} / \mathrm{min})=3.9 \times \mathrm{VO}_{2}(\mathrm{l} /$ $\min )+1.1 \mathrm{VCO}_{2}(1 / \mathrm{min})$

To assess cardiac high-phosphate energy metabolism, participants were scanned using 3T Philips Achieva scanner (Philips, Best, Netherlands) in a prone position. A $10 \mathrm{~cm}$ diameter ${ }^{31} \mathrm{P}$ surface coil (Pulseteq, UK) was utilized to transmit and receive the signal. Each participant was positioned into the magnet with the heart at isocenter. The position of the heart was confirmed using imaging from an in-built body coil. Using a cardiac-triggered breath-held field map, shimming was performed to enhance the homogeneity of the main magnetic field. A cardiac gated, slice-selective, onedimensional chemical shift imaging (1D-CSI) sequence was used. In order to eliminate liver contamination and 
prevent spectral contamination from the chest wall, a $7 \mathrm{~cm}$ slice selective pulse was applied foot-head and spatial presaturation of lateral skeletal muscle was done, respectively. Sixteen coronal phase-encoding steps were used, generating spectra from $10 \mathrm{~mm}$ slices [TR=heart rate; 192 averages at the center of k-space with cosinesquared acquisition weighting; acquisition time $20 \mathrm{~min}$ ). The locations of the spectral slices were overlaid onto an anatomical image and the first spectrum that arose entirely beyond the chest wall was selected. Quantification of PCr, $\gamma$-ATP, and 2,3-diphosphoglycerate (2,3-DPG) peaks was done using AMARES time domain fit routine of $\mathrm{jMRUI}$ processing software. The peak area of ATP was corrected for blood contamination by $1 / 6$ of the amplitude of combined 2,3-DPG peak after the fitting. After calculating PCr/ATP ratios, the ratios were corrected for saturation, with $\mathrm{T}_{1}$ values of cardiac $\mathrm{PCr}$ and ATP component taken from previous literature (Jones et al. 2010). Lastly, the flip angle was corrected using a calibration data set and a gadolinium-doped standard of $20 \mathrm{mM}$ phenyl phosphonic acid at the center of the coil.

All statistical analyses were performed using SPSS Statistics V.24.0. Normality of distribution was assessed using Q-Q plots and Shapiro-Wilk test. The relationship between variables of interest was assessed by Pearson's correlation coefficient (r). Partial correlation was also performed to control the covariates including age, body mass index, and physical activity. Data are presented as means \pm standard deviation (SD) unless otherwise stated. The level of statistical significance was indicated as $\mathrm{p}<0.05$.

\section{Results}

Demographic and physical activity characteristics of the study participants are shown in Table 1. Measures of body metabolic function including resting oxygen consumption, metabolic rate and glucose levels are presented in Table 2.

Analysis of cardiac metabolism using magnetic resonance spectroscopy revealed the mean $\pm \mathrm{SD}$ of cardiac high energy phosphate metabolism (PCr/ATP ratio) of $2.13 \pm 0.55$.

Association between cardiac high-energy phosphate metabolism and whole body metabolism is illustrated in Figure 1. No significant relationship was found between PCr/ATP ratio and resting metabolic rate, relative oxygen consumption, fasting plasma glucose levels, and 2-hour plasma glucose levels.

Table 1. Anthropometric characteristics of study participants.

\begin{tabular}{lc}
\hline Variable & Study Participants (n=35) \\
\hline Age, years & $55.7 \pm 14.0$ \\
Weight, $\mathrm{kg}$ & $67.7 \pm 11.2$ \\
Height, $\mathrm{cm}$ & $163 \pm 5.83$ \\
Body mass index, $\mathrm{kg} / \mathrm{m}^{2}$ & $25.5 \pm 3.71$ \\
Fat body mass, $\mathrm{kg}$ & $23.6 \pm 9.10$ \\
Physical Activity, steps/day & $11532 \pm 5422$ \\
\hline
\end{tabular}

Table 2. Measurements of whole body metabolism.

\begin{tabular}{lr} 
Variable & Study Participants \\
\hline Oxygen consumption, $\mathrm{ml} / \mathrm{min}$ & $244 \pm 35.9$ \\
Oxygen consumption, $\mathrm{ml} / \mathrm{kg} / \mathrm{min}$ & $3.68 \pm 0.71$ \\
Carbon dioxide production, $\mathrm{ml} / \mathrm{min}$ & $221 \pm 36.8$ \\
Respiratory exchange ratio & $0.90 \pm 0.07$ \\
Resting metabolic rate, $\mathrm{kcal} / \mathrm{day}$ & $1721 \pm 255$ \\
Fasting plasma glucose, $\mathrm{mmol} / \mathrm{l}$ & $4.87 \pm 0.50$ \\
2-hour plasma glucose, $\mathrm{mmol} / \mathrm{l}$ & $5.25 \pm 1.44$
\end{tabular}


Table 3 shows the results of partial correlation between $\mathrm{PCr} / \mathrm{ATP}$ ratio and resting metabolic rate, relative oxygen consumption, fasting plasma glucose levels, and 2-hour plasma glucose levels after that being
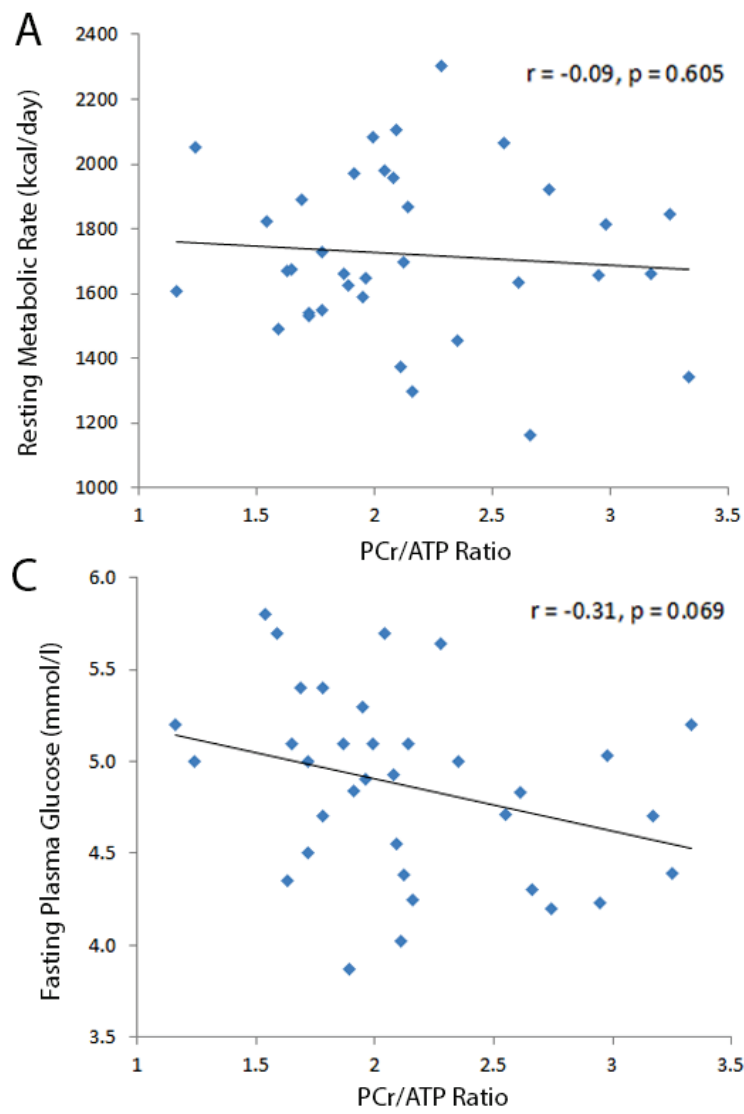

controlled for several covariates. Most correlations still showed weak and negative relationship between the variables even when the analysis was adjusted for age, BMI, fat mass, and physical activity.
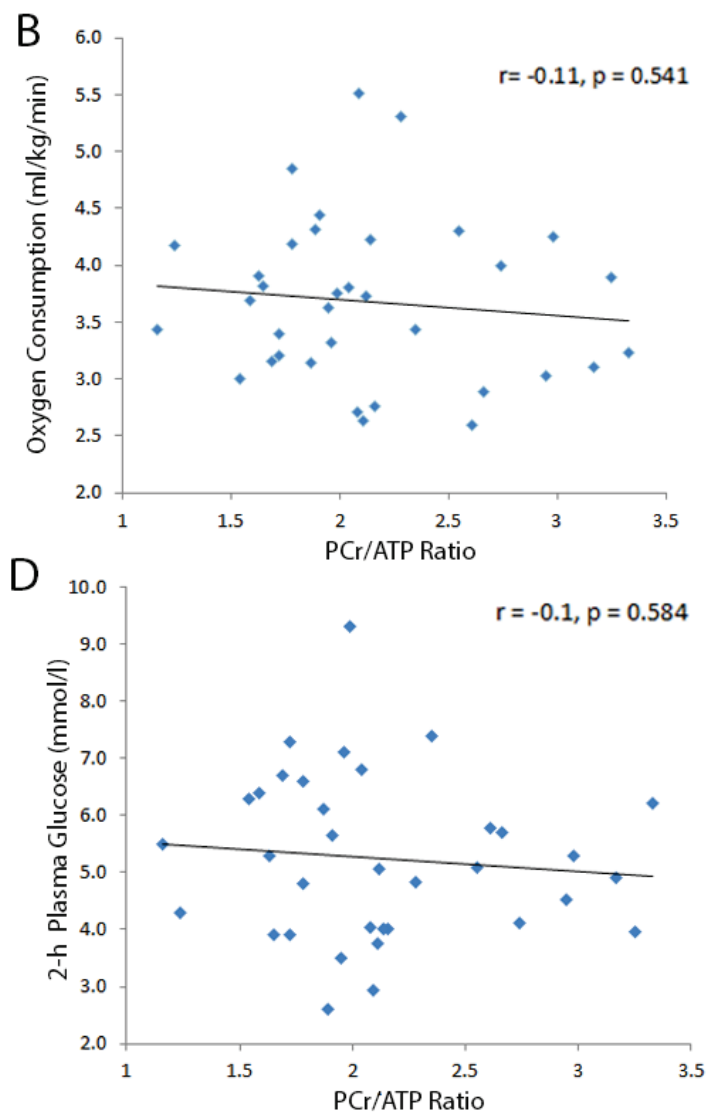

Fig. 1. Relationship between cardiac high-energy phosphate metabolism (PCr/ATP ratio) and (A) resting metabolic rate, (B) relative oxygen consumption, (C) fasting plasma glucose levels, and (D) 2-hour plasma glucose levels in all participants.

Table 3. Partial correlations between PCr/ATP ratio and measures of whole body metabolism.

\begin{tabular}{|c|c|c|c|c|c|}
\hline & & $\begin{array}{c}\text { Resting } \\
\text { Metabolic } \\
\text { Rate }\end{array}$ & $\begin{array}{c}\text { Relative Oxygen } \\
\text { Consumption }\end{array}$ & $\begin{array}{c}\text { Fasting Plasma } \\
\text { Glucose }\end{array}$ & $\begin{array}{c}\text { 2-h Plasma } \\
\text { Glucose }\end{array}$ \\
\hline \multirow{2}{*}{ Adjusted for age } & $\mathrm{r}$ & -0.15 & -0.14 & -0.10 & 0.16 \\
\hline & p-value & 0.41 & 0.42 & 0.58 & 0.37 \\
\hline \multirow{2}{*}{ Adjusted for BMI } & $\mathrm{r}$ & -0.09 & -0.21 & -0.31 & -0.08 \\
\hline & p-value & 0.63 & 0.24 & 0.07 & 0.65 \\
\hline \multirow{2}{*}{ Adjusted for fat mass } & $r$ & -0.09 & -0.28 & -0.29 & -0.06 \\
\hline & p-value & 0.63 & 0.11 & 0.09 & 0.74 \\
\hline Adjusted for physical & $\mathrm{r}$ & -0.14 & -0.32 & -0.31 & -0.03 \\
\hline activity & p-value & 0.45 & 0.06 & 0.08 & 0.86 \\
\hline Adjusted for age, BMI, fat & $\mathrm{r}$ & -0.25 & -0.37 & -0.22 & 0.19 \\
\hline $\begin{array}{l}\text { mass, and physical } \\
\text { activity }\end{array}$ & p-value & 0.18 & 0.43 & 0.24 & 0.31 \\
\hline
\end{tabular}




\section{Discussion}

The present study assessed the relationship between cardiac high-energy phosphate metabolism and whole body metabolism. It has been hypothesized that diminished cardiac metabolism plays a major role in the development of heart failure (Neubauer 2007). Evaluating the association between cardiac and whole body metabolism holds importance as it provides a better understanding of the interaction between the heart and body metabolic processes and their potential malleability with treatments.

The major finding of this study suggests that there is a weak and statistically non-significant relationship between cardiac high-energy phosphate metabolism and measures of whole body metabolic function, including resting metabolic rate, glucose levels, and oxygen consumption. Moreover, after controlling the correlation for covariates (i.e. age, BMI, fat mass, and physical activity), no significant relationship was found between PCr/ATP ratio and whole body metabolic variables.

Available studies that investigated the relationship between cardiac high-energy phosphate to body metabolism were only limited to evaluate the correlation between PCr/ATP ratio to glucose levels. Patients with type 1 and type 2 diabetes showed a decline in PCr/ATP ratio in comparison to the healthy controls (Metzler et al. 2002, Scheuermann-Freestone et al. 2003). Significant correlation was observed between PCr/ATP ratio and fasting plasma glucose $\left(\mathrm{r}^{2}=0.55, \mathrm{p}<0.05\right)$, although, no significant correlation was found in healthy subjects, which is in line with the present study (Scheuermann-Freestone et al. 2003). This suggests that presence of disease may enhance interaction between cardiac and body metabolism to be more pronounced. According to a longitudinal study (Nielson and Lange 2005), increased glucose levels are associated with increased risk of heart failure in non-diabetic adults and it may contribute to the development of heart failure. The possible mechanism to how glucose levels may affect the pathogenesis of heart failure is not known, but based on the present study it can be suggested that cardiac high energy phosphate metabolism may be independent from the mechanisms controlling whole body metabolism (Nielson and Lange 2005). The effectiveness of therapeutic interventions to improve glucose control has been previously reported (Guazzi et al. 2003, Nielson and Lange 2005). Improvement in insulin sensitivity resulted in improvement in exercise capacity in heart failure, but little evidence is available that improved glucose control can enhance cardiac energetics and function (Guazzi et al. 2003, Nielson and Lange 2005).

The analyses reveal weak, statistically nonsignificant relationship between cardiac PCr/ATP ratio, resting metabolic rate and oxygen consumption. This may imply that cardiac high-energy phosphate metabolism is independent from the body metabolic function. No study so far had evaluated relationship between cardiac metabolism and resting metabolic rate. Resting metabolic rate is altered in heart failure patients, although the mechanism was unknown (Poehlman et al. 1994). Further analysis included controlling for the covariates i.e. age, BMI, fat mass, and physical activity. However, even after accounting for these potentially confounding factors, results confirmed no significant association between cardiac PCr/ATP ratio and body metabolism. Lack of association between cardiac high-energy phosphate metabolism and body metabolism suggests that whole body metabolism should not be considered as a marker of cardiac metabolic health. Based on these findings it can be suggested that interventions known to improve whole body metabolism may not lead to improvement in cardiac metabolism.

This study has several potential limitations. The study participants were all women; therefore, the results may not be applicable to men. Furthermore, moderate sample size may increase the risk of statistical error.

In conclusion, the present study indicates a lack of significant relationship between cardiac PCr/ATP ratio and resting metabolic rate, oxygen consumption, and glucose levels. This finding suggests that whole body metabolism has no significant influence on cardiac highenergy phosphate metabolism. Further mechanistic studies are warranted to confirm or refute the lack of association between cardiac and body metabolism. Better understanding of molecular and cellular interactions between metabolic control of the heart and the rest of the body may lead to development to novel therapeutic targets and treatments.

\section{Conflict of Interest}

There is no conflict of interest.

\section{Acknowledgements}

The study was supported by the Newcastle NIHR Biomedical Research Centre in Ageing and Age Related Diseases. Dr. Jakovljevic is supported by Research 
Councils' UK Centre for Ageing and Vitality at Newcastle University (grant number L016354). The funding sources did not have involvement in aspect of the research. We thank all the participants of this study. We also acknowledge the significant contributions from Mei Jun Chen, the research nurse, and Tim Hodgson, Carol Smith, and Louise Morris, the research radiographers.

\section{References}

BEER M, SPINDLER M, SANDSTEDE JJW, REMMERT H, BEER S, KÖSTLER H, HAHN D: Detection of myocardial infarctions by acquisition-weighted 31P-MR spectroscopy in humans. J Magn Reson Imaging 20: 798-802, 2004. https://doi.org/10.1002/jmri.20185

COWIE MR: The heart failure epidemic: a UK perspective. Echo Res Pract 4: R15-R20, 2017. https://doi.org/10.1530/ERP-16-0043

ESTERHAMMER R, KLUG G, WOLF C, MAYR A, REINSTADLER S, FEISTRITZER H-J, METZLER B, SCHOCKE MFH: Cardiac high-energy phosphate metabolism alters with age as studied in 196 healthy males with the help of 31-phosphorus 2-dimensional chemical shift imaging. PLoS One 9: e97368, 2014. https://doi.org/10.1371/journal.pone.0097368

GUAZZI M, TUMMINELLO G, MATTURRI M, GUAZZI MD: Insulin ameliorates exercise ventilatory efficiency and oxygen uptake in patients with heart failure-type 2 diabetes comorbidity. J Am Coll Cardiol 42: 1044-1050, 2003. https://doi.org/10.1016/S0735-1097(03)00914-8

HARDY CJ, WEISS RG, BOTTOMLEY PA, GERSTENBLITH G: Altered myocardial high-energy phosphate metabolites in patients with dilated cardiomyopathy. Am Heart J 122: 795-801, 1991. https://doi.org/10.1016/0002-8703(91)90527-O

INGWALL JS, WEISS RG: Is the failing heart energy starved? On using chemical energy to support cardiac function. Circ Res 95: 135-145, 2004. https://doi.org/10.1161/01.RES.0000137170.41939.d9

JONES DEJ, HOLLINGSWORTH K, FATTAKHOVA G, MACGOWAN G, TAYLOR R, BLAMIRE A, NEWTON JL: Impaired cardiovascular function in primary biliary cirrhosis. Am J Physiology Gastrointest Liver Physiol 298: G764-G773, 2010. https://doi.org/10.1152/ajpgi.00501.2009

KANNEL WB, HJORTLAND M, CASTELLI WP: Role of diabetes in congestive heart failure: the Framingham study. Am J Cardiol 34: 29-34, 1974. https://doi.org/10.1016/0002-9149(74)90089-7

METZLER B, SCHOCKE MFH, STEINBOECK P, WOLF C, JUDMAIER W, LECHLEITNER M, LUKAS P, PACHINGER O: Decreased high-energy phosphate ratios in the myocardium of men with diabetes mellitus type I. J Cardiovasc Magn Reson 4: 493-502, 2002. https://doi.org/10.1081/JCMR-120016387

MOZAFFARIAN D, BENJAMIN EJ, GO AS, ARNETT DK, BLAHA MJ, CUSHMAN M, DAS SR, DE FERRANTI S, DESPRÉS JP, FULLERTON HJ, HOWARD VJ, HUFFMAN MD, ISASI CR, JIMÉNEZ MC, JUDD SE, KISSELA BM, LICHTMAN JH, LISABETH LD, LIU S, MACKEY RH, ET AL.: Heart Disease and Stroke Statistics-2016 Update: A Report From the American Heart Association. Circulation 133: e38-e360, 2016. https://doi.org/10.1161/CIR.0000000000000350

NEUBAUER S: The failing heart-an engine out of fuel. New Engl J Med 356: 1140-1151, 2007. https://doi.org/10.1056/NEJMra063052

NICHOLS GA, GULLION CM, KORO CE, EPHROSS SA, BROWN JB: The incidence of congestive heart failure in type 2 diabetes: an update. Diabetes Care 27: 1879-1884, 2004. https://doi.org/10.2337/diacare.27.8.1879

NIELSON C, LANGE T: Blood glucose and heart failure in nondiabetic patients. Diabetes Care 28: 607-611, 2005. https://doi.org/10.2337/diacare.28.3.607

POEHLMAN ET, SCHEFFERS J, GOTTLIEB SS, FISHER ML, VAITEKEVICIUS P: Increased resting metabolic rate in patients with congestive heart failure. Ann Intern Med 121: 860-862, 1994. https://doi.org/10.7326/0003-4819-121-11-199412010-00006

SAVARESE G, LUND LH: Global public health burden of heart failure. Card Fail Rev 3: 7-11, 2017. https://doi.org/10.15420/cfr.2016:25:2 
SCHEUERMANN-FREESTONE M, MADSEN PL, MANNERS D, BLAMIRE AM, BUCKINGHAM RE, STYLES P, RADDA GK, NEUBAUER S, CLARKE K: Abnormal cardiac and skeletal muscle energy metabolism in patients with type 2 diabetes. Circulation 107: 3040-3046, 2003. https://doi.org/10.1161/01.CIR.0000072789.89096.10

TENENBAUM A, FISMAN EZ: Impaired glucose metabolism in patients with heart failure: pathophysiology and possible treatment strategies. Am J Cardiovasc Drugs 4: 269-280, 2004. https://doi.org/10.2165/00129784-200404050-00001

VENTURA-CLAPIER R, GARNIER A, VEKSLER V: Energy metabolism in heart failure. J Physiol 555: 1-13, 2004. https://doi.org/10.1113/jphysiol.2003.055095

VENTURA-CLAPIER R, GARNIER A, VEKSLER V, JOUBERT F: Bioenergetics of the failing heart. Biochim Biophys Acta 1813: 1360-1372, 2011. https://doi.org/10.1016/j.bbamcr.2010.09.006

WEIR JBDB: New methods for calculating metabolic rate with special reference to protein metabolism. J Physiol 109: 1-9, 1949. https://doi.org/10.1113/jphysiol.1949.sp004363 